\title{
The frequency of vestibular disorders in developmentally delayed preschoolers with otitis media.
}

\author{
Roseann C Schaaf \\ Thomas Jefferson University
}

Follow this and additional works at: https://jdc.jefferson.edu/otfp

Part of the Occupational Therapy Commons

Let us know how access to this document benefits you

\section{Recommended Citation}

Schaaf, Roseann C, "The frequency of vestibular disorders in developmentally delayed preschoolers with otitis media." (1985). Department of Occupational Therapy Faculty Papers. Paper 17.

https://jdc.jefferson.edu/otfp/17

This Article is brought to you for free and open access by the Jefferson Digital Commons. The Jefferson Digital Commons is a service of Thomas Jefferson University's Center for Teaching and Learning (CTL). The Commons is a showcase for Jefferson books and journals, peer-reviewed scholarly publications, unique historical collections from the University archives, and teaching tools. The Jefferson Digital Commons allows researchers and interested readers anywhere in the world to learn about and keep up to date with Jefferson scholarship. This article has been accepted for inclusion in Department of Occupational Therapy Faculty Papers by an authorized administrator of the Jefferson Digital Commons. For more information, please contact: JeffersonDigitalCommons@jefferson.edu. 


\title{
The Frequency of Vestibular Disorders in Developmentally Delayed Preschoolers with Otitis Media
}

\author{
(middle ear functioning, occupational therapy, pediatrics, sensory \\ integration)
}

Roseann C. Schaaf

This study investigated the frequency of vestibular disorders in developmentally disabled preschoolers who did and who did not have a history of otitis media. Fifteen children with a history of otitis media and fifteen children with no history of otitis media were given two tests for vestibular functioning: the Southern California Postrotary Nystagmus Test (SCPNT) and the Lateral Labyrinthine Righting Reaction (LLRR), acting on the head. The scores on these tests were dichotomized, and a correlation between these two tests as measures of vestibular function was obtained. Because this correlation did not reach a satisfactory level, two a satisfactory level, two separate chisquare analyses were performed to examine the frequency of vestibular disorders with otitis media. Both tests showed a statistically significant difference in the incidence of vestibular disorders between the two groups of children; the group having otitis me- dia demonstrated more vestibular disorders. The SCPNT demonstrated more striking results than did LLRR. This finding is related to the two tests measuring different aspects of vestibular functioning; the separate chi-square analyses were performed to examine the frequency of vestibular disorders with otitis media. Both tests showed a statistically significant difference in the incidence of vestibular disorders between the two groups of children; the group having otitis media demonstrated more vestibular disorders. The SCPNT demonstrated more striking results than did LLRR. This finding is related to the two tests measuring different aspects of vestibular functioning; the SCPNT reflects semicircular canal functioning, and the LLRR reflects utricular and saccular functioning. The criteria used for LLRR (four seconds) also may have influenced the results obtained using this test.
$\mathbf{O}$ ccupational therapists and other professionals involved with developmentally and learning disabled children have clinically recognized the common occurrence of otitis media in conjunction with children diagnosed as having vestibular disorders $(1,2)$. As the vestibular system becomes more widely recognized as a major contributor to normal development, the interest in disturbances of this system also continues to grow. Additionally, the potential effect of otitis media on the vestibular apparatus has been a growing area of concern and research (3).

The role of the vestibular system in motor development, specifically equilibrium, muscle tonus, and oculo-motor control, has been documented by several leaders in the field of neurophysiology and neuroanatomy $(4,5)$. An association between vestibular and learning difficulties has been reported by

Roseann C. Schaaf, MEd, OTR, is an instructor, Department of Occupational Therapy, College of Allied Health Sciences, Thomas Jefferson University, Philadelphia, PA 19107. 
Ayres (6), Levinson (2), and deQuiros (7). Middle ear infections, or otitis media, have been noted as occurring in conjunction with or resulting in vestibular disturbances.

Several authors $(8,9)$ have alluded to the possible relationship between otitis media and vestibular disorders. Levinson (2) has even postulated a cause and effect relationship. Certainly, the anatomical relationship between these two systems cannot be overlooked because otitis media affects the middle ear, which is in close proximity to the inner ear, where the labyrinth (vestibular apparatus) is housed. This close relationship raises the question of the potential effects of otitis media on the labyrinths and consequently the vestibular system. However, few studies have investigated solely the potential relationship between otitis media and vestibular disorders. In particular, no studies have focused on the developmentally disabled child who is particularly susceptible to middle ear infections and is often found to have vestibular-related disorders.

\section{Literature Review}

Otitis media is one of the most common childhood illnesses (10, 11). Kessner, Snow, and Singer (12) suggest that $30 \%$ of all children between 6 months and 3 years old have evidence of middle ear disease. These high percentages were further verified by Howie (13) and Dobbie and Charles (14).

The high incidence of otitis media has led to many investigations of the long-term effects of chronic middle ear infections. It has been noted in the literature that otitis media may often exist undetected because of a lack of overt symptoms, which often results in a lowgrade, long-term infection and fur- ther complications (15). Symptoms of otitis media may include a buildup and discharge of fluid from the middle ear, a low-grade fever, gradual hearing loss, and, in more advanced cases, vertigo, deafness, nausea, and loss of equilibrium $(5,10,16)$.

The anatomical relationship of the middle and the inner ear and potential pathways for spread of infection have been discussed by several authors. Goycollea, Paparella, Juhn, and Carpentar (3) did a longitudinal study of the oval and round windows as potential pathways for the spread of infection from the middle ear into the inner ear where the labyrinthine apparatus may be affected. These researchers suggest that noxious elements pass through the round window membrane and cause inner ear pathological changes. A case study of Suga and Lindsay (17) supports these findings.

The anatomical relationship between middle ear infections and labyrinthine disorders has aiso been documented by Baloh and Honrubia (5), who state, "Infection from acute suppurative labyrinthitis usually has its origin in the middle ear or in cerebro-spinal fluid" (p 174). These researchers also propose that the round window is the pathway for spread of infection from middle to inner ear, eroding through bony wall and the round window.

Several authors $(18,19)$ have investigated whether the effect of potential hearing loss associated with otitis media is related to cognitive and language development. Menyuk (20) speculates that a permanent hearing loss is detrimental to cognitive and linguistic development along with academic achievement. A fluctuating or minimal loss may be as detrimental but may re- sult in delays in learning and language. He states that children who suffer early and frequent episodes of otitis media may have delayed acquisition of basic language and cognitive development but may have the potential to catch up. The lack of readiness or the delay in academic achievement noted in the population of children with recurrent or chronic otitis media may be related to a fluctuating or minimal hearing loss. Rapin (15) and Katz (21) also share Menyuk's (20) speculations.

The physiological and anatomical changes that occur at the level of the brain stem because of auditory deprivation associated with otitis media are discussed by Katz (21). He states, "Not only can sensory deprivation disrupt the function of a mature organ but it also can adversely affect the anatomical development of nerve cells when stimulation is restricted during early life" (p 879).

In line with Katz's (21) theory, several authors believe there's a relationship between otitis media and learning difficulties. Zinkus et al. (22) found that children with chronic and severe otitis media had substantial delays in speech and language development, auditory processing, reading, and spelling. He suggests early medical intervention in cases of chronic serous otitis media to prevent the development of specific learning disabilities. Evidence linking middle ear infections to learning difficulty is also cited by Ventry (23). However, he states that there is conflicting evidence that auditory deprivation is responsible for the difficulty.

The possibility that factors other than auditory deprivation are involved in learning disorders and otitis media is alluded to by Masters and Marsh (8). Their research rec- 
ognizes vestibular disorders as a possible sequel to otitis media and as a contributing factor in learning disabilities. As the vestibular system becomes increasingly recognized as a possible etiological factor in learning disabilities $(24,6,2)$, potential relationships beteen otitis media and vestibular disorders have been postulated $(2,8)$. Levinson (2) hypothesizes that otitis media may affect the vestibular proprioceptive system, which in turn may be a factor in dyslexia. He states, "The incidence of specific location on cerebellar-vestibular dysfunction underlying dysmetric dyslexia suggests the etiological possibility that 'harmless' ear infections during childhood may result in, or intensify, dysfunctioning within the labyrinthine-vestibular-cerebellar circuitry" (p 96).

Price and Teachman (1) also clinically noted a potential relationship between middle ear infections and vestibular functioning. Two of their subjects had changes in vestibular-related behaviors and postrotary nystagmus scores. In these cases, and in three others, the children with otitis media and upperrespiratory congestion had an increased sensitivity to vestibular stimulation in that they could not tolerate rotary or lateral motion, although they initially craved and enjoyed such stimulation. Reduction in postrotary nystagmus scores was also documented during these periods in two cases. Price and Teachman feel that upper-respiratory congestion and otitis media may affect vestibular functioning, as evidenced by increased hypersensitivity to motion with a tendency toward decreased postrotary nystagmus scores.

Research in this area of vestibular disorders and otitis media is relatively new and sparse. Disor- ders of the labyrinth as a long-term complication of otitis media and the potential relationship between otitis media and learning disorders is still not clear, but beginning evidence seems to support such an association. The purpose of this study was to investigate the frequency of vestibular disorders in developmentally disabled preschoolers who had otitis media.

The major thrust of the study was to verify the difference in the incidence of vestibular disorders in developmentally disabled preschoolers who had history of otitis media and those who did not.

\section{Methods}

\section{Subjects}

Thirty preschool children who were enrolled in or being evaluated by a local preschool program were selected as subjects. Each subject had to be 3.5 to 5.5 years old and be labeled as developmentally disabled by certified school psychologists. Developmentally disabled was defined according to the Federal Register (29) as,

A disability of a person which (i) is attributable to mental retardation, cerebral palsy, epilepsy, or autism; (ii) is attributable to any other condition of a person found to be related to mental retardation because such conditions result in similar impairment of intellectual functioning or adaptive behavior ...; (iii) or is attributable to dyslexia resulting in a disability described in paragraph (i) or (ii); iv originates before such a person attains eighteen; $(v)$ has continued indefinitely; or (vi) constitutes a substantial handicap to such persons' ability to function normally in society.

Fifteen of the subjects met the criteria for having otitis media, that is, they had four or more episodes of otitis media in their past history, with one episode within the last calendar year (April 1981-April
1982). Fifteen of the subjects met the criteria for not having otitis media, that is, they had no past history of otitis media and no episodes within the last calendar year.

To determine which children had otitis media, audiology, ENT (ear, nose, and throat), physicians', and parents' reports were reviewed, in addition to any other records contained in the subjects' charts that pertained to middle ear infections.

\section{Test Instruments}

Vestibular disorders were determined by using the Southern California Postrotary Nystagmus Test (SCPNT) and the Lateral Labyrinthine Righting Reaction, acting on the head (LLRR). Two test instruments were used to evaluate vestibular disorders because this ensured stronger indications of overall vestibular functioning (i.e., utricular and saccular, as well as semicircular canal functions).

Choosing tests of vestibular functioning for preschool children presents several difficulties: the availability of standardized tests for the preschool age group is limited and several standard clinical and neurological tests (prone-extension; standing balance, eyes closed; and Rhomberg) may be impractical. After reviewing the literature on acceptable tests, the SCPNT and the LLRR seemed the most appropriate and accurate measures. No other standardized tests or clinical observations of vestibular functioning were available at the time of this study.

The LLRR has been cited as an indicator of vestibular functioning, specifically of the utricle and saccule (25). Physiologically, a lateral tilt of the head is known to stimulate the otoliths in the saccular and utricular macules of the vestibular 
apparatus. This initiates reflexes that cause contraction of muscles opposing the force acting on the head and thus equilibrium is maintained. Specifically, in lateral labyrinthine righting, left lateral displacement of the head should cause an immediate contraction of muscles on the right side of the body and the head should return at once to the midline position.

The SCPNT is a well-documented and accepted indicator of function of the vestibular-ocular reflex activated by the horizontal semicircular canals (26). Ayres (26, 27) suggests that the evaluation of nystagmus using the SCPNT may be useful in determining vestibular disorders and in differentiating between specific types of dysfunction in learning-disabled children.

Rotation of the head (angular acceleration) causes initial endolymphatic flow, which displaces the cupula of the horizontal semicircular canal. Eye movements to the opposite side of rotation occur as a reflex to maintain visual fixation (5). When rotation suddenly stops, endolymphatic flow is in the direction of the rotation, and eye movements to the same side occur with an intermittent flick to the opposite side. This is known as postrotary nystagmus.

\section{Test Procedures}

Testing consisted of a 15-minute individual testing session with the examiner in a distraction-free room at each child's respective school. The LLRR was given first and was followed by the SCPNT. The SCPNT was given second because it is potentially disruptive to the child. Also, the SCPNT provides vestibular stimulation, which may affect the LLRR response. Both tests were administered and scored according to their standardized procedures. For the SCPNT, the norms published by Punwar (28) were used because they are standardized for 3- and 4-year-old children.

\section{Results}

Test data from 30 developmentally disabled preschool children were used to determine the incidence of vestibular disorders in the two groups of children. The data from each test were dichotomized, and each subject was categorized as either having or not having a vestibular disorder. For the SCPNT, raw scores were converted to standard scores according to the norms published in the SCPNT manual (26). These norms were used for the 3-to 5-year-old children because Punwar (28) found the norms to be valid for this age group. Standard scores falling below .9 $(-1.0$ to -2.2$)$ were given a " 1 ," which indicated a vestibular disorder; those of -.09 or above were given a dichotomized score of " 0 ," which indicated no vestibular disorder. No prolonged postrotary nystagmus occurred. LLRR raw scores were also dichotomized. The combined scores of four seconds or below were given a " 0 ," which indicated no vestibular disorder; scores four seconds and above received a " 1 ," which indicated there was vestibular disorder. Dichotomized and raw scores for each subject on both SCPNT and LLRR are given in Table 1. Before the data were analyzed, a phi correlation between the SCPNT and the LLRR was calculated to determine whether these two tests were highly correlated measures of vestibular functioning. The phi coefficient as shown in Table 2 was .505 . Although this correlation is significant, it is considered only moderately high, and therefore it was concluded that these two tests were independent measures of vestibular functions for the purposes of this study. Because of this, separate chi-squares were performed on each test rather than one chisquare on a single composite score of both tests (see Tables 3 and 4).

A chi-square analysis using the SCPNT as a measure of the inci- dence of vestibular disorders between subjects who did and did not have otitis media was performed. Dichotomized scores for SCPNT were used, and the presence or absence of otitis media was treated as a dichotomized variable. The chisquare analysis, as shown in Table 3 , illustrates that there is a difference in the incidence of vestibular disorders between groups of subjects. A corrected chi-square with $1 \mathrm{df}$ equals 6.806 , which is significant at the 0091 level.

A similar chi-square analysis was used with the LLRR to differentiate subjects who did and did not have otitis media. Dichotomized scores for LLRR and otitis media were used. A difference in the incidence of vestibular disorders between groups of children who did and did not have otitis media was found with the chi-square analysis $\left(\chi^{2}(1)=4.261, p=.0390\right)$ as illustrated in Table 4 , chi-square on LLRR by otitis media.

Also, an analysis of variance on raw SCPNT and LLRR scores was performed to determine whether there were differences between subjects who had otitis media and those who did not. Results showed a significant difference between scores on the SCPNT for both types of subjects. The $F$ ratio for the factor representing presence or absence of otitis media was significant $[\mathrm{F}(1,28)=12.55, p=.004]$. However, there was no difference between scores on the LLRR. The $F$ ratio was not significant $[\mathrm{F}(1,28)$ $=2.216, p=.476]$.

\section{Discussion and Conclusions}

The results of the chi-square analysis indicate that there was a significant difference in the incidence of vestibular disorders between developmentally disabled preschoolers who did and who did not have a history of otitis media. Both the SCPNT and the LLRR tests demonstrated this difference, although the SCPNT results were 
Table 1

Raw and Dichotomized Data for SCPNT and LLRP

\begin{tabular}{|c|c|c|c|c|c|c|}
\hline \multirow[b]{2}{*}{ No. } & \multirow[b]{2}{*}{$\begin{array}{l}\text { Otitis Media } \\
\text { Present }\end{array}$} & \multirow[b]{2}{*}{ Raw, sec } & \multicolumn{2}{|c|}{ SCPNT Scores } & \multicolumn{2}{|c|}{ LLR Scores } \\
\hline & & & SD & $\begin{array}{l}\text { Dichoto- } \\
\text { mized }\end{array}$ & Raw, sec & $\begin{array}{l}\text { Dichoto- } \\
\text { mized }\end{array}$ \\
\hline 1 & Yes & 18 & 0.0 & 0 & 0 & 0 \\
\hline 2 & Yes & 9 & -1.5 & 1 & 7 & 1 \\
\hline 3 & Yes & 16 & -0.6 & 0 & 5 & 0 \\
\hline 4 & Yes & 15 & -0.7 & 0 & 0 & 0 \\
\hline 5 & Yes & 8 & -1.6 & 1 & 6 & 1 \\
\hline 6 & Yes & 15 & -0.7 & 0 & 0 & 0 \\
\hline 7 & Yes & 6 & -1.9 & 1 & 3 & 0 \\
\hline 8 & Yes & 12 & -1.1 & 1 & 0 & 0 \\
\hline 9 & Yes & 19 & +0.2 & 0 & 7 & 1 \\
\hline 10 & Yes & 5 & -2.1 & 1 & 0 & 0 \\
\hline 11 & Yes & 9 & -1.5 & 1 & 9 & 1 \\
\hline 12 & Yes & 5 & -2.1 & 1 & 9 & 1 \\
\hline 13 & Yes & 8 & -1.6 & 1 & 5 & 1 \\
\hline 14 & Yes & 9 & -1.4 & 1 & 2 & 0 \\
\hline 15 & Yes & 11 & -1.2 & 1 & 2 & 1 \\
\hline 16 & No & 21 & +0.1 & 0 & 0 & 0 \\
\hline 17 & No & 24 & +0.5 & 0 & 0 & 0 \\
\hline 18 & No & 14 & -0.6 & 0 & 1 & 0 \\
\hline 19 & No & 16 & -0.6 & 0 & 3 & 0 \\
\hline 20 & No & 18 & -0.3 & 0 & 4 & 0 \\
\hline 21 & No & 18 & -.03 & 0 & 2 & 0 \\
\hline 22 & No & 19 & -0.1 & 0 & 4 & 0 \\
\hline 23 & No & 14 & -0.8 & 0 & 3 & 0 \\
\hline 24 & No & 15 & -0.7 & 0 & 3 & 0 \\
\hline 25 & No & 6 & -1.9 & 0 & 3 & 0 \\
\hline 26 & No & 26 & +0.8 & 0 & 4 & 0 \\
\hline 27 & No & 25 & +0.7 & 0 & 3 & 0 \\
\hline 28 & No & 14 & -0.6 & 0 & 2 & 0 \\
\hline 29 & No & 11 & -1.2 & 1 & 7 & 1 \\
\hline 30 & No & 24 & +0.5 & 0 & 3 & 0 \\
\hline
\end{tabular}

SCPNT, Southern California Postrotary Nystagmus Test; LLRR, Lateral Labyrinthine Righting Reaction, acting on the head.

Table 2

Phi Correlation of SCPNT and LLRR

\begin{tabular}{c|c|}
\hline \multicolumn{2}{c}{ LRRR } \\
$\begin{array}{c}\text { Without } \\
\text { Vestibular } \\
\text { Disorder }\end{array}$ & $\begin{array}{c}\text { With } \\
\text { Vestibular } \\
\text { Disorder }\end{array}$ \\
\hline 16 & 2 \\
\hline 5 & 7 \\
\hline 21 & 9 \\
\hline Phi $=.50483$. & 18 \\
\hline
\end{tabular}

more striking than those of the LLRR, with significance levels of .0091 and .0390 , respectively. These findings support Levinson's (2) theory regarding a connection between chronic middle ear infections and potential vestibular disorders and suggest a possible relationship beteen these two in developmentally disabled preschoolers.

Although the phi correlation between the two tests was significant $(.505)$, it was not considered high enough to regard these tests as interrelated measures of vestibular functioning (A. Sockloff, PhD, Professor of Statistics, Temple University, Philadelphia, PA, personal communication, May 1982). This is partially because the two tests measure two different aspects of the vestibular system: the SCPNT reflects semicircular canal function and the LLRR reflects utricle and saccule function (2, I Kimball, PhD, OTR, Director of Occupational Therapy, University of New England, Biddeford, ME, personal communication, January 1983). However, the correlation between the tests was significant, which supports an initial prediction that both tests together are a sufficient measure of overall vestibular functioning.

Using the chi-square analysis, however, it did not yield significant differences in an analysis of vari- ance between the subjects who have or did not have otitis media. Therefore, it is difficult to make statements when using the L.LRR as an indicator of vestibular functioning; however, the LLRR chisquare analysis lends support to the conclusion regarding differences in vestibular functioning between subjects. The SCPNT seems to be a good discriminator of vestibular functioning because the comparison of scores for this test between groups showed highly significant differences

The overall results of this study seem to suggest a significant incidence of vestibular disorders in developmentally disabled preschoolers who have a history of otitis media. Although this relationship warrants further investigation with more sophisticated testing and sampling procedures, those involved with this population about the potential relationship between inner and middle ear function should be cautioned. Routine screening of vestibular functioning for preschoolers having a history of chronic otitis media may be suggested.

Occupational therapists and other professionals need to be aware of the potential relationship between middle and inner ear pathology. Although further research in this area is necessary to verify and expand these results, there are several implications for occupational therapy. Children with chronic otitis media who exhibit developmental delays should be referred to occupational therapy for appropriate vestibular screening. Children who are presently seen in occupational therapy and develop acute episodes of otitis media should be monitored for changes in vestibular functioning. Additionally, a thorough history regarding middle ear health and functioning should be part of the ongoing occupational therapy record because it may yield information regarding past and present vestibular functioning. 
Table 3

Chi-Square on SCPNT (as a Measure of Vestibular Disorders) by Otitis Media

\begin{tabular}{|c|c|c|c|}
\hline \multirow{4}{*}{$\begin{array}{l}\text { Without vestibular disorder } \\
\text { With vestibular disorder }\end{array}$} & \multicolumn{2}{|c|}{ SCPNT } & \multirow[b]{3}{*}{18} \\
\hline & $\begin{array}{l}\text { Without } \\
\text { Otitis Media }\end{array}$ & $\begin{array}{l}\text { With } \\
\text { Otitis Media }\end{array}$ & \\
\hline & 13 & 5 & \\
\hline & 2 & 10 & 12 \\
\hline \multicolumn{4}{|c|}{ Corrected $\chi_{(1)}^{2}=6.806$, significance $=.0091$. } \\
\hline \multicolumn{4}{|c|}{$\begin{array}{l}\text { Table } 4 \\
\text { Chi-Square on LLRR (as a Measure of Vestibular Disorders) by Otitis Media }\end{array}$} \\
\hline & \multicolumn{2}{|c|}{ LLRR } & \multirow{4}{*}{$\begin{array}{r}22 \\
8\end{array}$} \\
\hline & $\begin{array}{l}\text { Without } \\
\text { Otitis Media }\end{array}$ & $\begin{array}{l}\text { With } \\
\text { Otitis Media }\end{array}$ & \\
\hline \multirow{2}{*}{$\begin{array}{l}\text { Without vestibular disorder } \\
\text { With vestibular disorder }\end{array}$} & $\overline{14}$ & 8 & \\
\hline & 1 & 7 & \\
\hline
\end{tabular}

Further research in this area is necessary to verify these results. Replication of this study using the same as well as other populations, including learning-disabled and normal preschool children, is recommended.

\section{Summary}

This study investigated the frequency of vestibular disorders in developmentally delayed preschoolers who did or did not have a history of otitis media. The children with a history of otitis media were found to have a significantly higher incidence of vestibular disorders than those without such a history. Both the SCPNT and the LLRR tests demonstrated these results. There were, however, slight differences between the tests. This was in part attributed to the fact that these two tests measure different areas of the vestibular system: the SCPNT measures semicircular canal function and the LLRR measures utricular and saccular function. This paper discusses the implications of these findings for occupational therapy and gives suggestions for further research.

\section{REFERENCES}

1. Price A, Teachman J: Otitis media, allergy, and vestibular function. Center for the Study of Sensory Inlegrative Dysfunction Newsletter. Pasadena, CA: Center for the Study of Sensory Integrative Dysfunction, 1978, Vol 6, no l

2. Levinson H: Dyslexia: A Solution to the Riddle. New York: Springer-Verlag, 1980

3. Govcollea MV, Paparella MM, Juhn SK, Carpentar A.M: Oval and round window changes in otitis media: Potential pathways between middle and inner ear. Laryngoscope 90 (8):1387-1391, 1980

4. Carpentar M: Human Neuroanatomy. Baltimore: Williams \& Wilkins, 1976

5. Baloh RW, Honrubia V: Clinical Neurophysiology of the Vestibular System. Pluiladelphia: Davis, I 979

6. Ayres AJ: Sensory Inlegration and Learning Disorders. Los Angeles: Western Psychological Services, 1975

7. DeQuiros J: Diagnosis of vestibular dising Disabilities 2:50-58, 1976

8. Masters 1., Marsh GE: Middle ear pathology as a factor in learning disabilities. J Learning Disabilities I 1:103-106, 1978

9. Witson W: Allergy in otology. Trans, Indiana Acad Opthalmological Otolaryngol 50: I-7, I967

10. Holvey DM: The Merck Manual of Diagnosis and Therapy, 12th edition. Rahwav, NJ: Merck, Sharp\& Dohme, 1972

11. Blustone C, Cantekin E: Design factors in the characterization and identification of otitis media and certain related conditions. Ann Otol, Rhinol Laryngol 60) (Otitis Media and Child Development. Speech, Language, and Education suppl 88):55-64, 1979

12. Kessner DM: Snow CK: Singer J: Assessment of Medical Care in Children, Contrasts in Health Status. Washington, DC: National Academy of Sciences, 1973, vol 3

13. Howie VM: Natural history of otitis orders in the learning disabled. J Learn- media, inn Otol Rhinol Laryngol 84(supp) 19):67-72,1975

14. Dobbie R, Charles B: Influence of otitis media on hearing and development. Ann Otol Rhinol Laryngol 60 (Otitis Media and Child Development, Speech. Language, and Education suppl 88(5, parl 2): 1977

15. Rapin 1: Conductive hearing loss effects on children's language and scholastic skills, a review of the literature. Ann Olol Rhinol Laryngol 60 (Otitis Media and Child Dev, Speech, Lang, Educ suppl 88(5): 1977

16. Nager G; Pathology of acute and chronic otitis media and their complications. Otitis Media Proceedings, A Glorig, K Gerwin, Editors. Springfield, IL: Thomas, 1972, pp 103-144

17. Suga F, Lindsay JR: Labyrinthitis ossificins. Ann Otol Rhinol Laryngol 86(no 1, part 1):17-29, 1977

18. Narmore RC: Influences of hearing impaimen on early language development. Ann Otol Rhinol Laryngol Speech, Lang, Educ suppl 88(5): 1977

19. Goethinger CP, Harrison C, Baer CJ: Sinall perceptive hearing loss: Its effect ii) school age children. Volta Rev $64: 124-131,1964$

20. Menyuk P: Design factors in the assessment of language development in children with otitis media. Ann Otol Rhinol Laryngol 60 (Otitis Media and Child Derelopment, Speech, and Language suppl 88, no 5): 1979

21. Kat7 J: The effects of conductive hearing loss on auditory function. ASHA 20(10):879-886, 1978

22. Zinkus PW, Goulieb ML, Shapiro M: Developmental psycho-educational sequelae of chronic otitis media. Am J Dis Child 132:1100-1104,1978

23. Ventry I: Effects of conductive hearing loss: Fact or fiction. I Speech Hear Disord 45:143-I56, 1980

24. DeQuiros J, Schrager O: Neuropsychological Fundamentals in Learning Disabilities. San Rafael, CA: Academic Therapy Publications, 1978

25. Fiorentino M: Reflex Testing Methods for Evaluating C.N.S. Development. Springfield, IL: Thomas, 1974

26. Ayres AJ: Southern California Postrotary Nystagmus Tesi Manual. Los Angeles: Western Psychological Services, 1977

27. Ayres AJ: Effects of Sensory Integrative Therapy on Learning Disabled Children (Final Research Report). Pasadena, CA: Center for Study of Sensory Integracive Dysfunction, 1976

28. Punwar A: Expanded normative data: southern California postrotary nystagmus test. Am J Occup Ther 36:183-187, 1982

29. Federal Register 45:250, December 1977

\section{RELATED READINGS}

Ayres AJ: Southern Cialifornia Sensory Integration Tests Manual. Los Angeles: Westerm Psychological Services, 1976

Brooks D: Impedance measurement in screening for auditory disorders. Hear Instr $25: 20-36,1974$ 